\title{
Time-driven ABC: análise bibliométrica de artigos acadêmicos divulgados em periódicos científicos entre 2004 \\ e 2015
}

Terence Machado Boina
Mestrado em andamento em Ciências Contábeis pela Universidade Federal do Rio de
Janeiro - UFRJ
Analista Administrativo da Agência Nacional do Cinema - ANCINE Avenida Pasteur, no 250, sala 251. Praia Vermelha. Rio de Janeiro/RJ. CEP: 22290-240

E-mail:tmboina@gmail.com

Ewerton Alex Avelar

Doutorado em andamento em Administração pela Universidade Federal de Minas Gerais - UFMG

Professor da Universidade Federal de Minas Gerais - UFMG Av. Pres. Antônio Carlos, № 6627. Pampulha. Belo Horizonte/MG. CEP: 31270-901

E-mail: ewertonaavelar@gmail.com

Antônio Artur de Souza Doutorado em Management Science pela Universidade de Lancaster, Reino Unido Professor da Universidade Federal de Minas Gerais - UFMG Av. Pres. Antônio Carlos, № 6627. Pampulha. Belo Horizonte/MG. CEP: 31270-901

E-mail: antonioarturdesouza@gmail.com

Pierre Ohayon

Doutor em Administração pela Universidade de São Paulo - USP Professor da Universidade Federal do Rio de Janeiro - UFRJ Avenida Pasteur, № 250, sala 251. Praia Vermelha. Rio de Janeiro/RJ. CEP: 22290-240 E-mail:pohayon@facc.ufrj.br

\section{RESUMO}

Este trabalho visou analisar características de estudos científicos sobre o time-driven activity-based costing (TDABC), publicados em periódicos no período de 2004 ao primeiro semestre de 2015. Analisaram-se 51 artigos por meio das seguintes técnicas: análise de conteúdo, estatística descritiva, teste do Qui-Quadrado e análise bibliométrica, com enfoque no índice de Lotka (Lei de Lotka). Constatou-se predomínio dos trabalhos empíricos sobre os teóricos e dos qualitativos em relação aos quantitativos e aos híbridos (quali-quanti). Constatou-se 0 uso de entrevistas (estruturadas e semiestruturadas) e de observação direta ou participante como as principais técnicas de coleta de dados. Verificou-se uma média de 2,5 autores por artigo, sendo que $74 \%$ dos artigos foram escritos por três autores ou menos. A análise sinalizou uma grande concentração de trabalhos em alguns poucos autores e uma grande quantidade de one-timers. Em relação ao TDABC, o incremento na precisão do 
Time-driven ABC: análise bibliométrica de artigos acadêmicos divulgados em periódicos científicos entre 2004 e 2015

Terence Machado Boina, Ewerton Alex Avelar, Antônio Artur de Souza, Pierre Ohayon

processo de apuração dos custos e a gestão da capacidade ociosa do processo produtivo foram os benefícios mais frequentemente destacados. Já as limitações mais reiteradas do referido método de custeio foram a necessidade de um sistema de informações estruturado, o custo de coleta de dados e os recursos consumidos que não possuem o tempo como variável de atribuição.

Palavras-chave: Time-Driven Activity Based Costing. Análise bibliométrica. Periódicos científicos.

\section{Time-driven ABC: bibliometric analysis of papers published in journals between} 2004 and 2015

\section{ABSTRACT}

This paper presents the results of a study that aimed at analyzing characteristics on the papers of time-driven activity-based costing (TDABC). It analyzed 51 articles, by following techniques: content analysis, descriptive statistics, chi-square test and bibliometric analysis, focusing on the Lotka index (Lotka's Law). It was found a predominance of empirical studies on the theoretical and qualitative over the quantitative and hybrids (qualitative and quantitative). Also found the use of interviews (structured and semi-structured) and direct observations or participant as the main data collection techniques. There was an average of 2.5 authors per article, with $74 \%$ of the articles were written by three authors or less. The analysis demonstrated a high concentration of jobs in a few authors and a lot of one-timers. Regarding the TDABC, increasing the accuracy of the calculation of costs and management of overcapacity in the production process were the benefits most often highlighted in the analyzed studies. Already the most repeated limitations of that cost method were the need for a structured information system, the cost of data collection and consumed resources that do not have the time as variable assignment.

Key words: Time-Driven Activity Based Costing. Bibliometric Analysis. Journals.

\section{INTRODUÇÃO}

Yilmaz (2008) afirma que as informações de custos usualmente são de substancial importância para o processo decisório dos gestores. Blocher, Chen e Lin (2002) salientam algumas decisões relevantes tomadas pelos gestores, que demandam informações de custos: rentabilidade e lucratividade de clientes/produtos/serviços, 
Time-driven ABC: análise bibliométrica de artigos acadêmicos divulgados em periódicos

científicos entre 2004 e 2015

Terence Machado Boina, Ewerton Alex Avelar, Antônio Artur de Souza, Pierre Ohayon

análise de processos produtivos e administrativos, precificação dos objetos de custos (serviços, produtos, clientes etc.), orçamentos e avaliação de desempenho.

Segundo Beaulieu e Lakra (2005), com vistas à evolução das informações de custos disponíveis às organizações, emergiu o custeio baseado em atividades (activitybased costing - $A B C$ ) em meados da década de 1980, notadamente com a publicação do trabalho de Cooper e Kaplan (1988). Conforme esses autores, o ABC visa melhorar as informações de custos geradas pelos métodos de custeio tradicionais, que geralmente alocam custos indiretos de forma bastante arbitrária aos objetos de custos e não oferecem um suporte gerencial apropriado aos seus usuários. Diversos autores, tais como Cokins (1999) e Hirsch (2000), salientam que o ABC se configura como um poderoso instrumento gerencial ao associar os custos inicialmente às atividades e, em seguida, aos objetos de custos, utilizando-se múltiplos e adequados direcionadores.

Por outro lado, no que tange ao processo de implementação, diversos estudos evidenciaram limitações relativas ao ABC (COBB; INNES; MITCHELL, 1992; GOSSELIN, 1997). Críticas a respeito do suporte gerencial do $A B C$ também foram descritas em outras pesquisas, tais como Geri e Ronen (2005). Até mesmo Robert Kaplan, em Kaplan e Anderson (2004), corroborou algumas restrições do método supramencionado, em especial, no que se refere ao seu elevado custo de implementação e de manutenção.

Em função disso, Kaplan e Anderson (2004) propuseram o time-driven activitybased costing (TDABC) com o propósito de atenuar ou superar as restrições do $A B C$ convencional. De acordo com aqueles autores, em relação ao $A B C$, o TDABC é uma abordagem menos dispendiosa, mais simples e célere de se implementar e manter. Ademais, essa nova abordagem também fornece outros benefícios potenciais às organizações, tais como: medição da capacidade não utilizada e modelagem de atividades complexas (KAPLAN; ANDERSON, 2004).

Embora a proposta de Kaplan e Anderson (2004) seja relativamente recente, alguns autores, como Varila et al. (2007), Cardinaels e Labro (2008) e Souza et al. (2010), já apresentaram críticas acerca do TDABC, especialmente no tocante à 
Time-driven ABC: análise bibliométrica de artigos acadêmicos divulgados em periódicos científicos entre 2004 e 2015

Terence Machado Boina, Ewerton Alex Avelar, Antônio Artur de Souza, Pierre Ohayon

complexidade da sua implantação em ambientes inconstantes e à aferição das equações de tempo (time equations) (um dos elementos fundamentais dessa nova abordagem).

Diante do exposto, este trabalho apresenta os resultados de uma pesquisa que visou analisar características de estudos científicos publicados em periódicos nacionais e internacionais no período de 2004 ao primeiro semestre de 2015 sobre o TDABC. Este trabalho aumenta o escopo de análise da pesquisa empreendida por Boina, Souza e Avelar (2014), que abrangeu o período de 2004 a 2013, com vistas a verificar se o panorama foi alterado ou se os achados revelam persistência da situação evidenciada por esses autores. Propuseram-se também os seguintes objetivos específicos: (a) identificar os estudos publicados a respeito do TDABC em periódicos nacionais e internacionais; (b) reproduzir as principais características desses artigos; (c) examinar a produção dos autores (particularmente, através da Lei de Lotka); e (d) identificar benefícios e limitações do TDABC.

O presente trabalho é segmentado em cinco seções (contando com esta introdução). Inicialmente, evidencia-se uma sucinta revisão da literatura sobre o TDABC (seção 2). Ulteriormente, na seção 3 , descreve-se a metodologia empregada para o desenvolvimento do estudo. Em seguida, os resultados da pesquisa são retratados e analisados (seção 4). Por fim, na seção 5 , as considerações finais são apresentadas, seguidas das referências.

\subsection{Time-Driven ABC}

Conforme Bruggeman, Anderson e Levant (2005), Robert Kaplan (um dos precursores do $A B C$ ) e Steven Anderson conceberam o TDABC. Kaplan e Anderson (2004) asseveraram que essa nova abordagem de geração de informações de custos poderia ser entendida como inovadora e mais aprimorada que o $A B C$ convencional, ultrapassando-o em uma série de aspectos e minimizando algumas de suas restrições.

Não obstante, Kaplan e Anderson (2007a) enfatizam que o ABC convencional foi um dos principais avanços em termos de ferramentas gerenciais das últimas décadas. 
Time-driven ABC: análise bibliométrica de artigos acadêmicos divulgados em periódicos científicos entre 2004 e 2015

Terence Machado Boina, Ewerton Alex Avelar, Antônio Artur de Souza, Pierre Ohayon

Contudo, segundo esses autores, o TDABC necessita de menos tempo de pesquisa e implementação em relação ao ABC convencional (BARRET, 2005). Pernot et al. (2007) ratificaram essa vantagem teórica em um estudo realizado em bibliotecas universitárias.

Segundo Varila et al. (2007), as equações de tempo são o cerne dessa nova abordagem. Tais equações (lineares) decorrem do reconhecimento e da modelagem das atividades relativas ao processo a ser analisado (BARRET, 2005). Essas equações visam retratar as distintas circunstâncias em que uma dada atividade pode ser desempenhada, considerando o uso de diferentes direcionadores e de suas interações.

A formação das equações de tempo, conforme Kaplan e Norton (2008), geralmente, são sustentadas em dados históricos e evidenciam como as transações e demandas consomem recursos. Tais equações são estimadas baseando-se na igualdade entre o tempo de processamento e o intervalo de tempo de cada atividade (HEIN et al., 2009). De forma algébrica, essa equação pode ser representada conforme a Equação 1.

$$
T P=\beta_{0}+\sum_{i=1}^{n} \beta_{i} X_{i}=\beta_{0}+\beta_{1} X_{1}+\beta_{2} X_{2}+\cdots+\beta_{n} X_{n}
$$

Onde:

TP $=$ Tempo de processamento,

$\beta_{0}=$ Tempo padrão para a execução da atividade básica,

$\beta_{i}=$ Tempos para a execução das atividades incrementais,

$X_{i}=$ Quantidade de atividades incrementais.

Os direcionadores de custos na abordagem do TDABC podem ser classificados como: contínuos, discretos ou indicadores (BRUGGEMAN; ANDERSON; LEVANT, 2005). Os dois primeiros são espécies de variáveis métricas, e o último é um tipo de variável não métrica. Um exemplo de direcionador contínuo é o peso de uma mercadoria. Já o número de itens de uma nota fiscal é um exemplo de direcionador discreto. Por sua vez, como direcionador indicador, pode-se citar o tipo de cliente. 
Time-driven ABC: análise bibliométrica de artigos acadêmicos divulgados em periódicos científicos entre 2004 e 2015

Terence Machado Boina, Ewerton Alex Avelar, Antônio Artur de Souza, Pierre Ohayon

Conforme Everaert et al. (2008), as seis etapas usualmente requeridas para a implementação do TDABC em uma organização são: (1) detecção dos recursos direcionados às atividades, separando-os em grupos; (2) mensuração dos custos de cada recurso; (3) estimação da capacidade prática das atividades; (4) cálculo da unidade de custo de cada recurso - divide-se o valor encontrado para cada grupo de recursos pelo valor obtido na etapa 3; (5) definição do tempo demandado por evento de uma atividade, baseando-se em distintos direcionadores de custos; e (6) multiplicação do custo unitário (obtido no passo 4) pelo tempo demandado por objeto de custo (obtido no passo 5).

Kaplan e Anderson (2007b) destacam vantagens a serem angariadas pelas organizações com o uso do TDABC: (a) simplicidade e celeridade na criação de um modelo acurado de informações de custos; (b) fácil interação com os sistemas de gestão integrada (Enterprise Resource Planning - ERP); (c) direcionadores que retratam as distintas características especiais observadas em algumas atividades; (d) disponibilidade de informações aprimoradas acerca da eficiência de processos e da capacidade utilizada de produção; e (e) aplicação em indústrias com grande e complexa diversidade de produtos, clientes e canais de distribuição. Everaert e Bruggeman (2007), Varila et al. (2007) e Pernot et al. (2007) confirmam esses benefícios teóricos apresentados pelos proponentes do TDABC.

Pernot et al. (2007) também realçam a celeridade do processo, o fato de as equações de tempo modelarem operações mais complexas e a possibilidade de 0 TDABC se integrar com outras ferramentas gerenciais, tal como o Balanced Scorecard (BSC). Já Demeere et al. (2009) ressaltam que as informações de custos oriundas do TDABC possibilitaram melhorias operacionais, análises setoriais mais precisas de rentabilidade e suporte à tomada de decisões de investimentos nas organizações estudadas.

Por outro lado, Varila et al. (2007), Cardinaels e Labro (2008) e Souza et al. (2012) fizeram algumas críticas a respeito do TDABC no tocante à: (i) necessidade de coleta de um substancial volume de dados para se mensurar as equações de tempo; (ii) 
Time-driven $A B C$ : análise bibliométrica de artigos acadêmicos divulgados em periódicos científicos entre 2004 e 2015

Terence Machado Boina, Ewerton Alex Avelar, Antônio Artur de Souza, Pierre Ohayon

dificuldade em se estimar tais equações em ambientes pouco estruturados; e (iii) subjetividade inerente na mensuração de tempo dos funcionários para cada atividade executada.

\section{METODOLOGIA}

Conforme a classificação de Sampieri, Collado e Lucio (2006), a pesquisa, cujos resultados são apresentados neste trabalho, pode ser classificada, com base em seus objetivos, como descritiva. Esse tipo de pesquisa se propõe a produzir uma representação das pessoas, eventos ou situações (SAUNDERS; LEWIS; THORNHILL, 2009). Particularmente, esta pesquisa buscou descrever características de estudos comunicados publicamente em periódicos nacionais e internacionais sobre o TDABC.

Quanto aos procedimentos técnicos utilizados, conforme Gil (1996), esta pesquisa é considerada bibliográfica, haja vista que sua fonte se baseou em materiais já elaborados - dados secundários (artigos publicados em periódicos nacionais e internacionais). Para análise dos dados, usou-se a técnica de análise de conteúdo que, segundo Bardin (2009), é uma função heurística que aumenta a propensão a descobertas e uma função de administração de provas, no sentido de afirmação ou não dos dados coletados. Nesse caso, analisou-se o conteúdo de artigos acadêmicos.

Utilizou-se uma abordagem quantitativa, pois foram empregadas análises estatísticas para descrever as características das referidas pesquisas. Ainda se analisaram qualitativamente os conteúdos dos artigos a fim de identificar e descrever benefícios e limitações enfatizados pelos autores acerca da utilização empírica do TDABC.

Tendo em vista a potencial grande quantidade de publicações a respeito do tema pesquisado, buscou-se delimitar sua esfera de alcance, conforme fizeram Boina, Souza e Avelar (2014). Nesse sentido, por meio de uma amostragem não probabilística por conveniência, verificaram-se artigos científicos publicados nas línguas portuguesa e inglesa em periódicos disponíveis em bases de dados nacionais e internacionais 
Time-driven ABC: análise bibliométrica de artigos acadêmicos divulgados em periódicos científicos entre 2004 e 2015

Terence Machado Boina, Ewerton Alex Avelar, Antônio Artur de Souza, Pierre Ohayon

(Science Direct e SCOPUS, acessadas por meio do Portal de Periódicos da Coordenação de Aperfeiçoamento de Pessoal de Nível Superior - CAPES) que versavam sobre o TDABC. Complementarmente, também foram realizadas buscas no Google Acadêmico $\AA$. Os termos utilizados na pesquisa dos artigos científicos, nas referidas bases de dados, foram: "Time-driven Activity Based Costing", "Time-driven $A B C$ " e "TDABC".

Inspirado em Oliveira (2002), selecionaram-se especificamente periódicos científicos em virtude da significativa relevância destes meios de comunicação da produção científica. A seleção dos trabalhos acadêmicos se fundamentou notadamente nos seguintes parâmetros: (i) fossem publicados nas línguas portuguesa ou inglesa; (ii) abordassem o tema 'TDABC'; e (iii) fossem disponibilizados gratuitamente para download nos sítios eletrônicos pesquisados. No Quadro 1, evidenciam-se os 42 periódicos que se adequaram aos critérios ressaltados anteriormente. 
Time-driven ABC: análise bibliométrica de artigos acadêmicos divulgados em periódicos científicos entre 2004 e 2015

Terence Machado Boina, Ewerton Alex Avelar, Antônio Artur de Souza, Pierre Ohayon

\begin{tabular}{|c|c|c|}
\hline ISSN & Título & Sigla \\
\hline $1467-6281$ & A Journal Accounting, Finance and Business Studies & ABACUS \\
\hline $1980-4814$ & ABCustos & ABCustos \\
\hline $1467-6303$ & Accounting Forum & AF \\
\hline 17493374 & Accounting History & $\mathrm{AH}$ \\
\hline $1546-3141$ & American Journal of Roentgenology & AJR \\
\hline $1528-1132$ & Clinical Orthopaedics and Related Research & CORR \\
\hline $0103-734 X$ & Contabilidade Vista \& Revista & CVR \\
\hline $1984-882 X$ & Enfoque: Reflexão Contábil & ERC \\
\hline 10429247 & Engineering Management Journal & EMJ \\
\hline $1755-053 X$ & Financial Management & FM \\
\hline 178012 & Harvard Business Review & HBR \\
\hline $2227-9032$ & Healthcare & Healthcare \\
\hline $0168-8510$ & Health Policy & $\mathrm{HP}$ \\
\hline $2073-7122$ & Interdisciplinary Journal of Contemporary Research in Business & IJCRB \\
\hline $1833-8119$ & International Journal of Business and Management & IJBM \\
\hline 0959-6119 & International Journal of Contemporary Hospitality Management & $\mathrm{IJCHM}$ \\
\hline $0960-0035$ & International Journal of Physical Distribution \& Logistics Management & IJPDLM \\
\hline $0972690 x$ & IUP Journal of Accounting Research \& Audit Practices & JARAP \\
\hline $1832-5912$ & Journal of Accounting \& Organizational Change & JAOC \\
\hline $0748-5751$ & Journal of Accounting Education & JAE \\
\hline $0967-5426$ & Journal of Applied Management Accounting Research & JAMAR \\
\hline 0973-0729 & Journal of Healthcare Management & JHM \\
\hline $1933-0693$ & Journal of Neurosurgery & $\mathrm{JN}$ \\
\hline $1539-2570$ & Journal of Pediatric Orthopaedics & JPO \\
\hline $1464-9055$ & Library Collections, Acquisitions, \& Technical Services & LCATS \\
\hline $0143-5124$ & Library Management & LM \\
\hline $1044-5005$ & Management Accounting Research & MAR \\
\hline $1092-0684$ & Neurosurgical Focus & NF \\
\hline 0194-5998 & Otolaryngology-Head and Neck Surgery & OHNS \\
\hline $1467-9302$ & Public Money \& Management & PMM \\
\hline $1176-6093$ & Qualitative Research in Accounting \& Management & QRAM \\
\hline $2176-9036$ & Revista Ambiente Contábil & Ambiente \\
\hline $2237-0099$ & Revista de Estudos Contábeis & REC \\
\hline $1982-3967$ & Revista de Informação Contábil & $\mathrm{RIC}$ \\
\hline $1809-3337$ & Revista Universo Contábil & RUC \\
\hline $1558-7967$ & The Accounting Review & AR \\
\hline $0020-7063$ & The International Journal of Accounting & IJA \\
\hline 0099-1333 & The Journal of Academic Librarianship & JAL \\
\hline $1097-0053$ & The Journal of Corporate Accounting \& Finance & JCAF \\
\hline $0140-6736$ & The Lancet & $\overline{T L}$ \\
\hline $1478-3371$ & Total Quality Management \& Business Excellence & TQMBE \\
\hline $1098-3015$ & Value in Health & JVAL \\
\hline
\end{tabular}

Quadro 1: Informações relativas aos periódicos analisados

Fonte: Dados da pesquisa e adaptado de Boina, Souza e Avelar (2014). 
Time-driven ABC: análise bibliométrica de artigos acadêmicos divulgados em periódicos científicos entre 2004 e 2015

Terence Machado Boina, Ewerton Alex Avelar, Antônio Artur de Souza, Pierre Ohayon

Realizou-se o download de aproximadamente 110 artigos que apresentaram relação com o tema 'TDABC', segundo os mecanismos de busca supramencionados e que foram disponibilizados de forma gratuita. A partir de uma análise inicial, averiguouse que 51 estudos abordavam efetivamente aquele tema, no período de 2004 ao primeiro semestre de 2015, no formato Portable Document Format (.pdf).

Em seguida, os artigos escolhidos foram classificados, em consonância com Boina, Souza e Avelar (2014), segundo as categorias apresentadas a seguir: (i) periódico; (ii) ano de publicação; (iii) autores; (iv) segmento de mercado; (v) tipo de estudo - teórico ou empírico; (vi) abordagem metodológica - quantitativa, qualitativa ou qualitativa e quantitativa (quali-quanti); (vii) foco do artigo; (viii) utilização de outro método/ferramenta científico em conjunto com o TDABC; (ix) esfera de aplicação público ou privado; $(x)$ país de realização da pesquisa; e (xi) benefícios e limitações observados pelos autores sobre o uso do TDABC.

Os dados foram compilados a partir do emprego do software Statistical Package for Social Science (SPSS) versão 17.0 e, em complemento, do software Microsoft ${ }^{\circledR}$ Excel (MS-Excel) 2013. Usou-se estatística descritiva para análise dos dados com o propósito de, conforme Maroco (2010), descrever as principais características dos dados analisados. Ainda se recorreu à estatística do Qui-Quadrado, que é proveitosa para examinar a significância de uma associação observada em uma tabulação cruzada e define a presença de uma alocação sistemática entre duas variáveis observadas (MALHOTRA; BIRKS, 2007). Já para desenvolver a análise bibliométrica dos trabalhos selecionados, com base em Nascimento et al. (2009), utilizou-se o índice de Lotka (Lei de Lotka), calculado pela fórmula apresentada na Equação 2.

$$
a_{n}=a_{1} \times \frac{1}{n^{0}}
$$

Onde: $a_{n}$ corresponde ao número de autores com $\mathrm{n}$ artigos; $a_{1}$ corresponde ao número de autores que publicaram apenas um artigo; $n$ corresponde ao número de artigos; e c corresponde ao coeficiente de Lotka $(\approx 2)$. 
Time-driven ABC: análise bibliométrica de artigos acadêmicos divulgados em periódicos científicos entre 2004 e 2015

Terence Machado Boina, Ewerton Alex Avelar, Antônio Artur de Souza, Pierre Ohayon

Pode-se dizer que as principais limitações da pesquisa apresentada neste trabalho são o subjetivismo inerente à classificação dos artigos, de acordo com as categorias preestabelecidas, e o enfoque direcionado a periódicos científicos, de algumas bases de dados, como veículos de comunicação pública das pesquisas sobre o tema estudado. Somente foram analisados os artigos científicos acessíveis ao pesquisador de forma gratuita. Portanto, periódicos científicos que demandavam recursos financeiros para acessar os artigos não foram considerados nesta pesquisa.

Ademais, não foram considerados outros meios de comunicação pública e outras bases de dados em função da amostragem não probabilística por conveniência empregada, bem como com fins de comparação, para se adequar metodologicamente à pesquisa desenvolvida por Boina, Souza e Avelar (2014). Ademais, foram analisados trabalhos escritos apenas nas línguas inglesa e portuguesa, o que também restringe 0 alcance e a generalização dos resultados.

\section{APRESENTAÇÃO E DISCUSSÃO DOS RESULTADOS}

\subsection{Análise descritiva dos estudos analisados}

$\mathrm{Na}$ Tabela 1, evidencia-se, em frequência absoluta (Abs.) e relativa (\%), o número de estudos analisados acerca do TDABC por periódico. A referida Tabela foi segmentada em dois períodos (2004-2009 e 2010-2015), para fins de apresentação. No total, foram examinados 51 artigos de 42 periódicos distintos. Por sua vez, a Figura 1 apresenta a evolução do número total de publicações identificadas ao longo dos anos.

No ano de 2014, como pode ser observado na Figura 1, houve o maior número de publicações sobre o tema TDABC (11 artigos ou $21,6 \%$ do total), seguido do primeiro semestre de 2015 (9 artigos ou 17,6\% do total) e do ano de 2010 (8 publicações ou $15,7 \%$ do total). Este estudo, assim, apresenta um novo achado, pois demonstra um aumento da produção nos últimos dois anos, diferentemente de Boina, Souza e Avelar (2014), que evidenciaram uma redução em 2013 (último ano estudado pelos referidos autores). 
Time-driven ABC: análise bibliométrica de artigos acadêmicos divulgados em periódicos científicos entre 2004 e 2015

Terence Machado Boina, Ewerton Alex Avelar, Antônio Artur de Souza, Pierre Ohayon

Por outro lado, assim como observado por Boina, Souza e Avelar (2014), nos anos de 2005 e 2006, não se verificaram estudos sobre o TDABC, o que, em parte, pode se explicar em virtude do reduzido lapso temporal entre a publicação do trabalho de Kaplan e Anderson na Harvard Business Review em 2004, a compreensão da metodologia, sua aplicação e geração de resultados, a oficialização por meio de um trabalho acadêmico, o exame, a avaliação, a aceitação por parte do periódico e a ulterior publicação.

Conforme pode ser verificado pela análise da Figura 1, não houve linearidade, aumentos ou decréscimos claramente constantes na quantidade de publicações ao longo do tempo. Houve um aumento de pesquisas sobre o tema entre 2004 e 2010, seguido de uma abrupta queda, um súbito crescimento e, depois, outro vertiginoso declínio. Por fim, em 2014 e no primeiro semestre de 2015, o número de publicações nos periódicos analisados aumentou substancialmente.

Ademais, de acordo com os dados da Tabela 1, é possível dizer que não há aglomeração significativa de trabalhos acadêmicos acerca do tema TDABC em determinados periódicos. Pelo contrário, observa-se uma disseminação de estudos nos diversos periódicos analisados. Os periódicos JAMAR, JCAF, CORR, IJPDLM, LM e QRAM apresentaram as maiores quantidades de artigos publicados sobre o TDABC no período analisado (4, 3, 2, 2, 2 e 2 respectivamente, ou $8 \%, 6 \%, 4 \%, 4 \%, 4 \%$ e $4 \%$ do total), o que pode se configurar um reduzido grau de concentração de publicações. Semelhante resultado foi observado por Boina, Souza e Avelar (2014). Assim, o aumento de publicações nos últimos anos (2014 e 2015) ocorreu de forma dispersa entre os periódicos, o que parece sinalizar certa aceitação do tema nos diversos periódicos analisados. 
Time-driven ABC: análise bibliométrica de artigos acadêmicos divulgados em periódicos científicos entre 2004 e 2015

Terence Machado Boina, Ewerton Alex Avelar, Antônio Artur de Souza, Pierre Ohayon

Tabela 1: Número de artigos analisados sobre TDABC (por periódico, entre 2004-2009 e 2010-2015)

\begin{tabular}{|c|c|c|c|c|c|c|}
\hline \multirow{4}{*}{ Periódico/Sigla } & \multicolumn{4}{|c|}{ Período } & \multirow{2}{*}{\multicolumn{2}{|c|}{ Total }} \\
\hline & \multicolumn{2}{|c|}{ 2004-2009 } & \multicolumn{2}{|c|}{ 2010-2015 } & & \\
\hline & \multicolumn{6}{|c|}{ Frequência } \\
\hline & Abs. & $\%$ & Abs. & $\%$ & Abs. & $\%$ \\
\hline ABACUS & 0 & 0 & 1 & 3 & 1 & 2 \\
\hline ABCustos & 0 & 0 & 1 & 3 & 1 & 2 \\
\hline $\mathrm{AF}$ & 0 & 0 & 1 & 3 & 1 & 2 \\
\hline $\mathrm{AH}$ & 0 & 0 & 1 & 3 & 1 & 2 \\
\hline AJR & 0 & 0 & 1 & 3 & 1 & 2 \\
\hline CORR & 0 & 0 & 2 & 5 & 2 & 4 \\
\hline CVR & 1 & 8 & 0 & 0 & 1 & 2 \\
\hline ERC & 1 & 8 & 0 & 0 & 1 & 2 \\
\hline EMJ & 0 & 0 & 1 & 3 & 1 & 2 \\
\hline FM & 1 & 8 & 0 & 0 & 1 & 2 \\
\hline HBR & 1 & 8 & 0 & 0 & 1 & 2 \\
\hline Healthcare & 0 & 0 & 1 & 3 & 1 & 2 \\
\hline $\mathrm{HP}$ & 1 & 8 & 0 & 0 & 1 & 2 \\
\hline IJCRB & 0 & 0 & 1 & 3 & 1 & 2 \\
\hline IJBM & 0 & 0 & 1 & 3 & 1 & 2 \\
\hline $\mathrm{IJCHM}$ & 0 & 0 & 1 & 3 & 1 & 2 \\
\hline IJPDLM & 2 & 15 & 0 & 0 & 2 & 4 \\
\hline JARAP & 1 & 8 & 0 & 0 & 1 & 2 \\
\hline JAOC & 1 & 8 & 0 & 0 & 1 & 2 \\
\hline JAE & 1 & 8 & 0 & 0 & 1 & 2 \\
\hline JAMAR & 1 & 8 & 3 & 8 & 4 & 8 \\
\hline JHM & 0 & 0 & 1 & 3 & 1 & 2 \\
\hline $\mathrm{JN}$ & 0 & 0 & 1 & 3 & 1 & 2 \\
\hline JPO & 0 & 0 & 1 & 3 & 1 & 2 \\
\hline LCATS & 0 & 0 & 1 & 3 & 1 & 2 \\
\hline LM & 0 & 0 & 2 & 5 & 2 & 4 \\
\hline MAR & 0 & 0 & 1 & 3 & 1 & 2 \\
\hline NF & 0 & 0 & 1 & 3 & 1 & 2 \\
\hline OHNS & 0 & 0 & 1 & 3 & 1 & 2 \\
\hline PMM & 0 & 0 & 1 & 3 & 1 & 2 \\
\hline QRAM & 0 & 0 & 2 & 5 & 2 & 4 \\
\hline Ambiente & 0 & 0 & 1 & 3 & 1 & 2 \\
\hline REC & 0 & 0 & 1 & 3 & 1 & 2 \\
\hline $\mathrm{RIC}$ & 0 & 0 & 1 & 3 & 1 & 2 \\
\hline RUC & 0 & 0 & 1 & 3 & 1 & 2 \\
\hline $\mathrm{AR}$ & 1 & 8 & 0 & 0 & 1 & 2 \\
\hline IJA & 0 & 0 & 1 & 3 & 1 & 2 \\
\hline JAL & 1 & 8 & 0 & 0 & 1 & 2 \\
\hline JCAF & 0 & 0 & 3 & 8 & 3 & 6 \\
\hline
\end{tabular}


Time-driven ABC: análise bibliométrica de artigos acadêmicos divulgados em periódicos científicos entre 2004 e 2015

Terence Machado Boina, Ewerton Alex Avelar, Antônio Artur de Souza, Pierre Ohayon

\begin{tabular}{|c|c|c|c|c|c|c|}
\hline TL & 0 & 0 & 1 & 3 & 1 & 2 \\
\hline TQMBE & 0 & 0 & 1 & 3 & 1 & 2 \\
\hline JVAL & 0 & 0 & 1 & 3 & 1 & 2 \\
\hline Total & $\mathbf{1 3}$ & $\mathbf{1 0 0}$ & $\mathbf{3 8}$ & $\mathbf{1 0 0}$ & $\mathbf{5 1}$ & $\mathbf{1 0 0}$ \\
\hline
\end{tabular}

Fonte: Dados da pesquisa e adaptado de Boina, Souza e Avelar (2014).

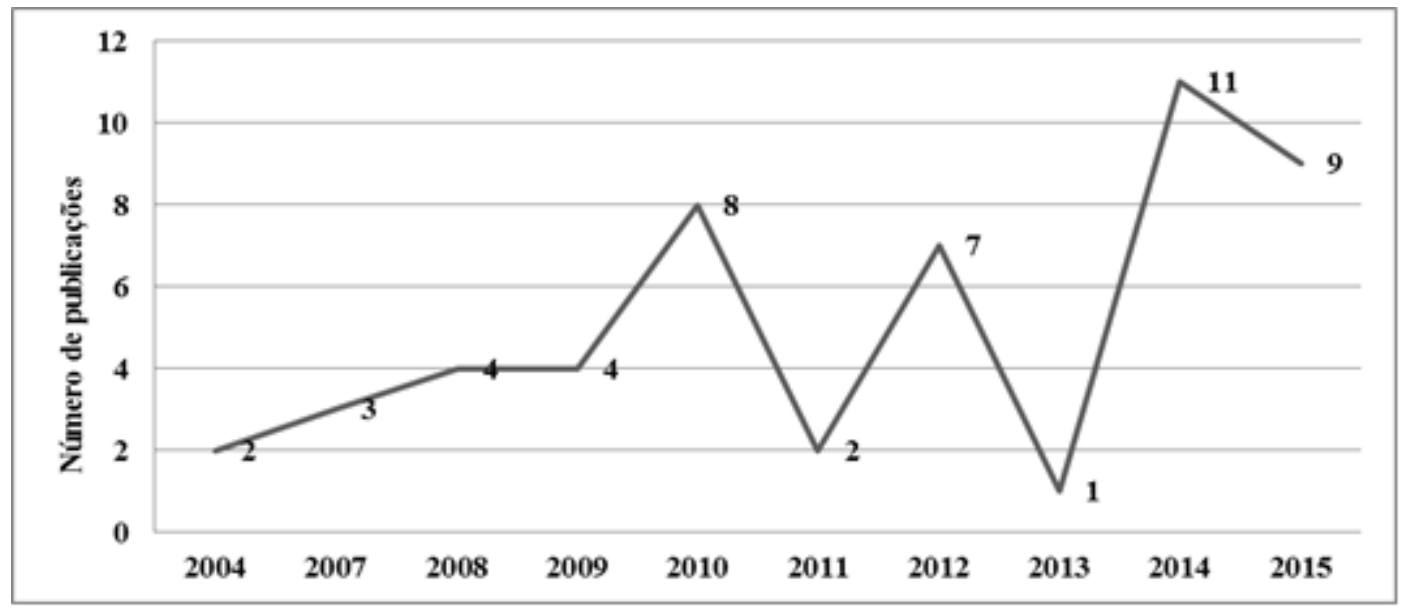

Figura 1: Evolução do número total de publicações Fonte: Dados da pesquisa e adaptado de Boina, Souza e Avelar (2014).

Já na Figura 2, é explicitado o número de artigos publicados ao longo do período de análise, categorizando-os em teóricos ou empíricos. Por intermédio da referida figura, demonstra-se a preponderância dos artigos empíricos ( $71 \%$ do total) sobre os teóricos. Ressalta-se que o resultado foi superior ao observado em Boina, Souza e Avelar (2014) - 68\%, o que sugere um aumento mais que proporcional dos artigos baseados em pesquisas empíricas nos últimos anos. Isso revela uma maior aplicação prática da metodologia, com vistas a experimentar a ferramenta proposta e reproduzir as experiências alcançadas ao invés de somente discutir os princípios e as implicações do modelo apresentado por Kaplan e Anderson (2004).

Nos anos de 2007 e 2008, houve a maior concentração relativa de artigos empíricos nos anos analisados. Já em 2013, o único artigo analisado sobre a temática do TDABC apresentou abordagem teórica. Em termos absolutos, o primeiro semestre de 2015 evidenciou a maior quantidade de artigos empíricos. Destaca-se que o teste do 
Time-driven ABC: análise bibliométrica de artigos acadêmicos divulgados em periódicos científicos entre 2004 e 2015

Terence Machado Boina, Ewerton Alex Avelar, Antônio Artur de Souza, Pierre Ohayon

Qui-Quadrado não demonstrou que a distribuição entre o tipo de estudo e o ano de publicação foi significativamente assimétrica, ou seja, a distribuição dos estudos teóricos e empíricos entre os anos é relativamente homogênea do ponto de vista estatístico.

Na Figura 3, demonstra-se a abordagem empregada no desenvolvimento das pesquisas no que tange ao ano das publicações, sendo considerados nesta classificação somente os estudos empíricos. Verifica-se uma supremacia de estudos qualitativos sobre os demais ( $58,8 \%$ do total de estudos analisados), com exceção de 2011, 2014 e do primeiro semestre de 2015. Nestes primeiros dois anos, houve um equilíbrio no número de trabalhos com abordagem qualitativa, quantitativa e qualiquanti. Já no primeiro semestre de 2015, o número de estudos com abordagem qualiquanti foi superior aos qualitativos. Salienta-se que o predomínio dos estudos qualitativos foi inferior ao observado por Boina, Souza e Avelar (2014) - 74\%, ou seja, parece existir uma tendência dos pesquisadores em utilizarem outras abordagens em estudos mais recentes.

Verifica-se que, no final do período examinado, o número de estudos que empregaram uma abordagem metodológica quantitativa e quali-quanti foi superior aos qualitativos, notadamente em função dos trabalhos publicados no primeiro semestre de 2015. Salienta-se que o teste do Qui-quadrado não vislumbrou resultados significativos ao se examinar a distribuição das diferentes abordagens empreendidas nos estudos. 
Time-driven ABC: análise bibliométrica de artigos acadêmicos divulgados em periódicos científicos entre 2004 e 2015

Terence Machado Boina, Ewerton Alex Avelar, Antônio Artur de Souza, Pierre Ohayon

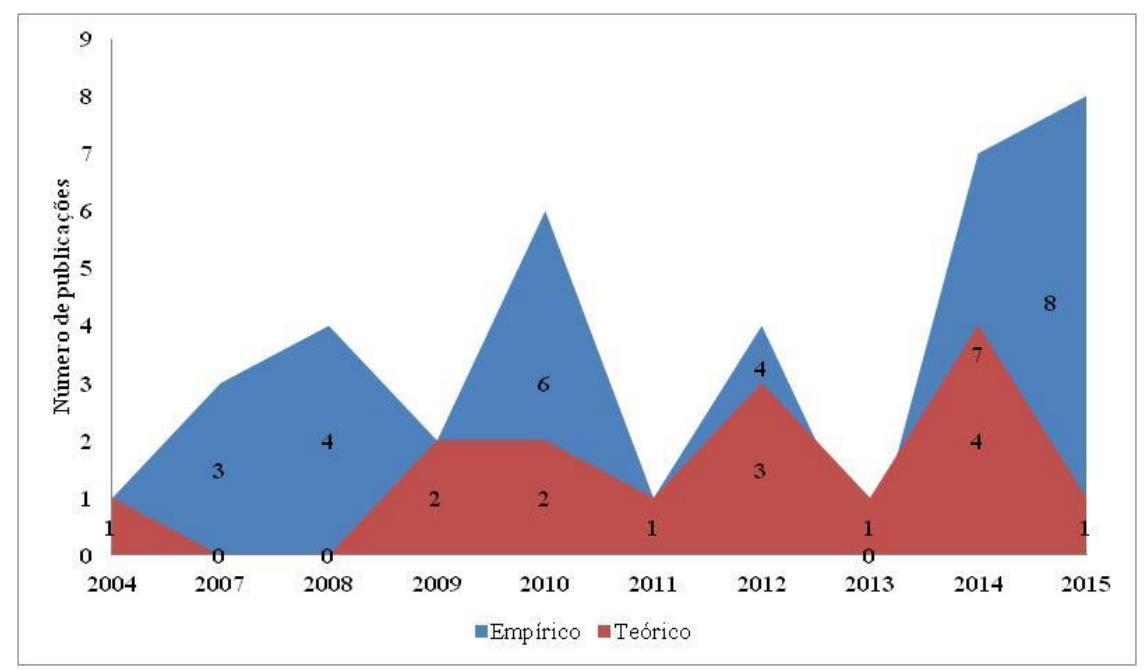

Figura 2: Número de artigos teóricos e empíricos por ano

Fonte: Dados da pesquisa e adaptado de Boina, Souza e Avelar (2014).

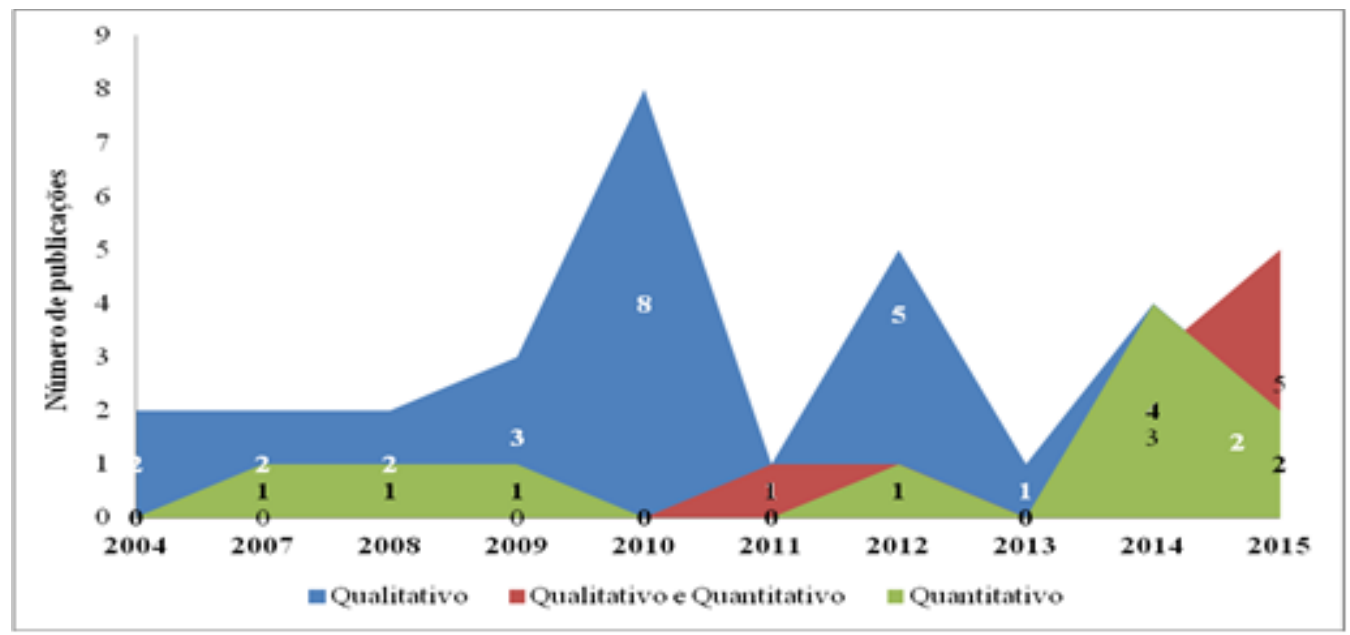

Figura 3: Número de artigos classificados por natureza metodológica e por ano Fonte: Dados da pesquisa e adaptado de Boina, Souza e Avelar (2014).

As entrevistas (estruturadas e semiestruturadas) e a observação direta ou participante, observadas em $60 \%$ e $22 \%$ dos artigos, respectivamente, se destacaram como as principais técnicas de coleta de dados empregadas nos trabalhos examinados. A pesquisa documental (16\% dos artigos) também foi bastante usada. Conforme Boina, Souza e Avelar (2014), o emprego dessas técnicas se justifica em função de o processo de implantação do TDABC normalmente demandar conversas com as pessoas que 
Time-driven ABC: análise bibliométrica de artigos acadêmicos divulgados em periódicos científicos entre 2004 e 2015

Terence Machado Boina, Ewerton Alex Avelar, Antônio Artur de Souza, Pierre Ohayon

executam atividades cotidianas, assim como a necessidade de observá-las para identificar, compreender e, até mesmo, cronometrar os tempos de execução de tais atividades. Salienta-se que esses resultados são similares aos obtidos por aqueles autores em seu estudo.

Ressalta-se que, aproximadamente $75 \%$ dos artigos focaram, sobretudo, a temática do TDABC. Importante enfatizar que esse percentual é superior ao observado por Boina, Souza e Avelar (2014) - 62\%. Tal resultado indica um aumento no enfoque do TDABC nos trabalhos publicados nos últimos dois anos. Os demais trabalhos pesquisados associavam essa nova abordagem do $A B C$ a distintas ferramentas gerenciais, por exemplo: BSC, Sistemas de Controle Gerencial, Métodos equivalentes de Estimação e Gestão de Custos, Sistemas de Avaliação de Desempenho, Teoria das Filas, Teoria das Restrições e Processo de Análise Hierárquica.

$\mathrm{Na}$ Tabela 2, são demonstrados os segmentos de mercado nos quais os artigos empíricos foram realizados. Pode-se perceber que o setor terciário (especialmente serviços) é majoritariamente pesquisado (aproximadamente $82 \%$ dos artigos) em relação à aplicação do TDABC. Nesse setor, os estudos analisados enfocaram hospitais, bibliotecas, hotéis, serviços de tecnologia da informação ( $\mathrm{TI})$, logística etc. Já o setor secundário (indústria) foi pesquisado cerca de 18\% dos casos, especialmente em organizações de produção por encomenda. Observa-se um aumento no número de artigos na área do setor terciário em relação ao trabalho de Boina, Souza e Avelar (2014) - 62\%, ou seja, parece existir uma tendência cada vez maior no aumento dos estudos aplicados ao setor de serviços. 
Time-driven ABC: análise bibliométrica de artigos acadêmicos divulgados em periódicos científicos entre 2004 e 2015

Terence Machado Boina, Ewerton Alex Avelar, Antônio Artur de Souza, Pierre Ohayon

Tabela 2: Número de autores por segmento de mercado

\begin{tabular}{|c|c|c|}
\hline \multirow{2}{*}{ Segmento de mercado } & \multicolumn{2}{|c|}{ Frequência } \\
\cline { 2 - 3 } & Abs. & Relativa (\%) \\
\hline Serviços em geral & 22 & 43 \\
\hline Hospital & 14 & 27 \\
\hline $\begin{array}{c}\text { Produção por } \\
\text { encomenda }\end{array}$ & 7 & 14 \\
\hline Biblioteca & 4 & 8 \\
\hline Hotel & 2 & 4 \\
\hline Alimentos & 2 & 4 \\
\hline Total & $\mathbf{5 1}$ & $\mathbf{1 0 0}$ \\
\hline
\end{tabular}

Fonte: Dados da pesquisa e adaptado de Boina, Souza e Avelar (2014).

No que se refere às pesquisas desenvolvidas em hospitais, especificamente, Porter e Kaplan (2014) descreveram a necessidade de se estimar os custos dos serviços hospitalares para se formar os preços de tais serviços. Relevante enfatizar a posição desses autores, que são dois ícones das pesquisas em administração e gestão de custos, citados nas pesquisas examinadas, e que podem ter influenciado o surgimento de trabalhos sobre o TDABC naquele tipo de organização. Robert Kaplan, conforme dito anteriormente, foi um dos precursores do TDABC, e Michael Porter é um dos mais influentes autores da administração contemporânea, ambos da Harvard Business School.

Além disso, mais de $71 \%$ dos artigos empíricos pesquisados no período foram feitos no setor privado e o restante no setor público. Esse percentual observado no setor privado é inferior ao verificado por Boina, Souza e Avelar (2014) - 80\%. Assim, tem-se que, nos últimos anos, apesar da supremacia das pesquisas no setor privado, há um aumento mais que proporcional de pesquisas realizadas no setor público. Salienta-se que o teste do Qui-Quadrado não demonstrou que a distribuição entre o setor de aplicação do estudo e o ano de publicação foi significativamente assimétrica, ou seja, a distribuição dos estudos por setor entre os anos é relativamente homogênea. 
Time-driven ABC: análise bibliométrica de artigos acadêmicos divulgados em periódicos científicos entre 2004 e 2015

Terence Machado Boina, Ewerton Alex Avelar, Antônio Artur de Souza, Pierre Ohayon

\subsection{Análise de autoria das publicações}

Durante a pesquisa, mais de 100 autores distintos nos artigos analisados foram identificados. Na Tabela 3, demonstra-se o número de autores por artigo na temática do TDABC. Tem-se uma média de aproximadamente 2,5 autores por artigo, sendo que $74 \%$ dos artigos foram escritos por três autores ou menos. Observa-se um aumento do número de autores por artigo em relação ao observado por Boina, Souza e Avelar (2014) (2,1 autores). Essa constatação é reforçada pela redução do número de artigos escritos por três autores ou menos nos últimos anos, uma vez que aqueles autores verificaram o percentual de $84 \%$.

No caso dos periódicos internacionais, os autores mais prolíficos, exceto os precursores Kaplan e Anderson, foram os europeus Werner Bruggeman (com quatro trabalhos acadêmicos), Yves Levant e Filip Roodhooft (com três artigos publicados). Já em termos de periódicos nacionais, os autores mais produtivos, com três artigos publicados, foram Antônio Artur de Souza, Ewerton Alex Avelar e Terence Machado Boina, que fizeram parceria em todos os trabalhos.

Tabela 3: Número de autores por artigo

\begin{tabular}{|c|c|c|}
\hline NNo de autores & \multicolumn{2}{|c|}{ Frequência } \\
\cline { 2 - 3 } por artigo & Absoluta & Relativa (\%) \\
\hline 1 & 4 & 8 \\
\hline 2 & 15 & 29 \\
\hline 3 & 19 & 37 \\
\hline 4 & 7 & 14 \\
\hline 5 ou mais & 6 & 12 \\
\hline Total & $\mathbf{5 1}$ & $\mathbf{1 0 0}$ \\
\hline
\end{tabular}

Fonte: Dados da pesquisa.

Por sua vez, a Figura 4 representa graficamente uma análise da temática do TDABC e revela resultados divergentes do padrão proposto pela Lei de Lotka. Averiguou-se que a produção de artigos teve substancial número de one-timers (autores com apenas uma publicação), corroborando os achados de Boina, Souza e Avelar (2014). Enquanto se esperava que mais de 5 autores publicassem 6 ou mais 
Time-driven ABC: análise bibliométrica de artigos acadêmicos divulgados em periódicos científicos entre 2004 e 2015

Terence Machado Boina, Ewerton Alex Avelar, Antônio Artur de Souza, Pierre Ohayon

artigos no período, o resultado indicou que nenhum autor atingiu esse grau de publicação. Se, por um lado, esse resultado aparenta ser algo valioso para o avanço da área devido à dispersão de estudos, de outro modo, a pesquisa sobre essa temática talvez possa sofrer influência e ficar suscetível à disposição de um pequeno número de pesquisadores e seus vieses pessoais.

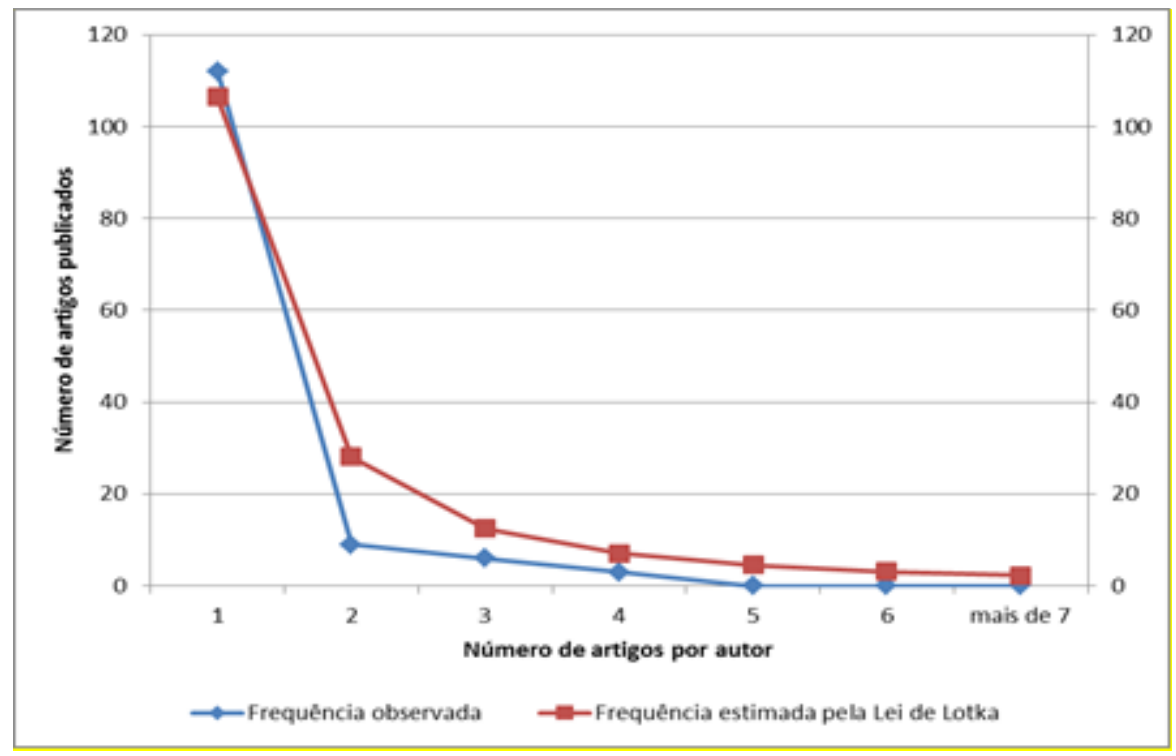

Figura 4: Análise da autoria dos artigos em relação ao estimado pela Lei de Lotka Fonte: Dados da pesquisa

\subsection{Benefícios e limitações do TDABC}

Outra constatação da pesquisa diz respeito aos benefícios e às limitações do TDABC evidenciados nos artigos analisados. Tais informações são apresentadas no Quadro 2, complementando o que fora inicialmente delineado por Boina, Souza e Avelar (2014). Verificou-se que os estudos dos últimos dois anos enfocaram os seguintes benefícios advindos da implementação do TDABC: (i) identificação de atividades com capacidade ociosa; e (ii) estimação de custos mais fidedigna (e consequente formação de preços mais coerente). Por outro lado, as seguintes limitações foram reforçadas nos últimos anos, conforme os estudos examinados: (a) aumento do custo de coleta de dados e dificuldade na elaboração das equações de 
Time-driven ABC: análise bibliométrica de artigos acadêmicos divulgados em periódicos científicos entre 2004 e 2015

Terence Machado Boina, Ewerton Alex Avelar, Antônio Artur de Souza, Pierre Ohayon

tempo; (b) geração de informações de custos tendenciosas; (c) demanda por um sistema de informações estruturado para dar suporte a uma base de dados robusta; e (d) relativo grau de subjetividade no processo de estimação dos tempos.

\begin{tabular}{|c|c|}
\hline Benefícios & Limitações \\
\hline $\begin{array}{l}\text { - Suporte ao processo orçamentário (LIU et al., } \\
\text { 2008) } \\
\text { - Foco na necessidade de recursos das } \\
\text { atividades envolvidas na produção de } \\
\text { resultados (LIU et al., 2008) } \\
\text { - Maior envolvimento e inclusão dos } \\
\text { colaboradores (LIU et al., 2008) } \\
\text { - Identificação de atividades com capacidade } \\
\text { ociosa (DALMÁCIO et al., 2007; } \\
\text { CARDINAELS; LABRO, 2008; DALCI et al., } \\
\text { 2010; TANIŞ; ÖZYAPICI, 2012; SOUZA et al., } \\
\text { 2012; FISHER; KRUMWIEDE, } 2012 \text {; } \\
\text { WERNKE; JUNGES; LEMBECK, 2015; } \\
\text { BASUKI; RIEDIANSYAF, } \\
\text { CAMPANALE; CINQUINI; TENUCCI; 2014; } \\
\text { BALAKRISHNAN; GOICO; ARJMAND, 2015) } \\
\text { - Agregação de valor nos processos de tomada } \\
\text { de decisão sobre rentabilidade de produtos e } \\
\text { serviçOS (EVERAERT et al., 2008; DALCI et } \\
\text { al., 2010) } \\
\text { - Melhoria na confiabilidade dos dados e } \\
\text { informações (CARDINAELS; LABRO, 2008) } \\
\text { consequente formação de preços mais } \\
\text { condizente com a realidade (EVERAERT et } \\
\text { al., 2008; PERNOT et al., 2007; ECKERT et } \\
\text { al., 2012; BASUKI; RIEDIANSYAF, 2014; } \\
\text { AKHAVAN; WARD; BOZIC, 2015; HUANG et } \\
\text { al., 2014; KAPLAN et al., 2014; MISONO; }\end{array}$ & $\begin{array}{l}\text { - Dificuldade de se mensurar o trabalho exigido } \\
\text { por agentes externos (LIU et al., 2008) } \\
\text { - Ambientes de grande flexibilidade e } \\
\text { imprevisibilidade (SOUZA et al., 2010) } \\
\text { - Aumento do custo de coleta de dados e } \\
\text { dificuldade na elaboração das equações de } \\
\text { tempo (CLELAND, 2004; MORTAJl; } \\
\text { BAGHERPOUR; MAZDEH, 2014; MISONO; } \\
\text { OKLU; PRABHAKAR, 2015; McLAUGHLIN et } \\
\text { al., 2014) informações de custos } \\
\text { - Geração de } \\
\text { tendenciosas (HOOZÉE; BRUGGEMAN, } \\
\text { 2010; MORTAJI; BAGHERPOUR; MAZDEH, } \\
\text { 2014) } \\
\text { - Demanda por um sistema de informações } \\
\text { estruturado para dar suporte a uma base de } \\
\text { dados robusta (STOUTHUYSEN et al., 2010; } \\
\text { GERVAIS et al., 2010; ÖKER; ADIGÜZEL, } \\
\text { 2010; SOUZA et al., 2012; MORTAJ; } \\
\text { BAGHERPOUR; MAZDEH, 2014) } \\
\text { - Necessidade de revisão constante de } \\
\text { controles internos (GERVAIS et al., 2010; } \\
\text { RATNATUNGA; WALDMANN, 2010; SOUZA } \\
\text { et al., 2012) Relativo grau de subjetividade no processo de } \\
\text { estimação dos tempos (CARDINAELS; } \\
\text { LABRO, 2008; SOUZA et al., 2012; BASUKI; } \\
\text { RIEDIANSYAF, 2014) }\end{array}$ \\
\hline
\end{tabular}


Time-driven ABC: análise bibliométrica de artigos acadêmicos divulgados em periódicos científicos entre 2004 e 2015

Terence Machado Boina, Ewerton Alex Avelar, Antônio Artur de Souza, Pierre Ohayon

\begin{tabular}{|c|c|}
\hline $\begin{array}{l}\text { OKLU; PRABHAKAR, 2015) } \\
\text { Diminuição do volume de dados a serem } \\
\text { coletados e analisados (GERVAIS et al., } \\
2010 \text { ) } \\
\text { Maior amplitude de comparabilidade entre os } \\
\text { setores da organização por meio de um } \\
\text { benchmarking interno (DEMEERE et al., } \\
2009 \text { ) } \\
\text { Melhoria da compreensão dos gestores em } \\
\text { relação aos diversos } \\
\text { organizacionais (DEMEERE et al., 2009; } \\
\text { DALCl et al., 2010) } \\
\text { Utilização de um sistema de informações } \\
\text { simples (STOUTHUYSEN et al., 2010; } \\
\text { colpA }\end{array}$ & 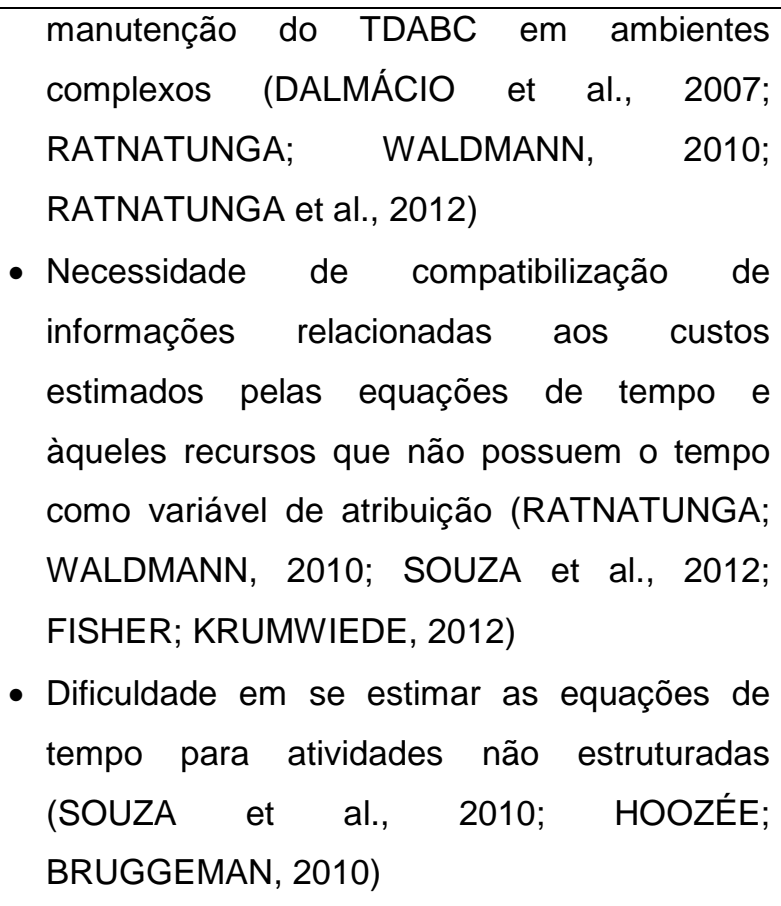 \\
\hline
\end{tabular}

Quadro 2: Compilação por autores dos benefícios e limitações identificados nos artigos analisados Fonte: Dados da pesquisa e adaptado de Boina, Souza e Avelar (2014).

É possível dizer que o principal benefício ressaltado nos artigos analisados na pesquisa foi o aumento da precisão no processo de apuração dos custos e, consequentemente, melhoria das informações para o processo de tomada de decisão dos gestores. Dentre essas decisões, os pesquisadores dos artigos examinados destacaram o processo orçamentário, a formação de preços, as avaliações de desempenho e as decisões de investimento e financiamento. Ainda foi realçada a possibilidade de se identificar e gerenciar a capacidade ociosa do processo produtivo, 0 que é apresentado pela literatura como um importante diferencial do TDABC em relação às demais metodologias de gestão de custos.

No que tange às principais limitações, a necessidade de um sistema de informações estruturado para dar suporte a uma base de dados robusta foi bastante descrita pelas pesquisas. O custo de coleta de dados e a elaboração das equações de tempo, especialmente pelo considerável grau de subjetividade das estimativas, também foram enfatizadas pelas pesquisas analisadas. Por fim, a necessidade de 
Time-driven ABC: análise bibliométrica de artigos acadêmicos divulgados em periódicos científicos entre 2004 e 2015

Terence Machado Boina, Ewerton Alex Avelar, Antônio Artur de Souza, Pierre Ohayon

compatibilização de informações de custos, cujos recursos consumidos não possuem o tempo como variável de atribuição, foi outra limitação do TDABC indicada pelas pesquisas.

\section{CONSIDERAÇÕES FINAIS}

Os resultados apresentados neste artigo podem ser considerados relevantes em virtude da abordagem de análise bibliométrica com as categorias utilizadas na pesquisa sobre o TDABC, aumentando o escopo em relação a Boina, Souza e Avelar (2014). Revelou-se um aumento considerável das pesquisas empíricas sobre o TDABC, em especial nos periódicos internacionais, a partir de 2014, o que pode ser um indício de legitimação da metodologia de gestão de custos nas organizações. Assim, é possível dizer que o panorama foi, em parte, alterado em relação aos achados de Boina, Souza e Avelar (2014).

Em 2014 e no primeiro semestre de 2015, publicaram-se 20 artigos, o que representa aproximadamente $40 \%$ de toda a publicação sobre o tema no período analisado, o que pode ser considerado um importante achado deste trabalho. Ressaltase também a quantidade de pesquisas realizadas em hospitais nos Estados Unidos da América, com o fito de verificar os custos gerados por aquelas organizações como base para se estimar os preços dos serviços prestados.

Identificou-se supremacia dos estudos empíricos sobre os teóricos e dos qualitativos em relação aos quantitativos e os híbridos (quali-quanti). Todavia, essa predominância foi reduzida nos últimos anos da análise, o que parece sinalizar uma tendência dos pesquisadores em utilizarem outras abordagens em estudos mais recentes. Também se constatou maior quantidade de aplicação de entrevistas (estruturadas e semiestruturadas) e de observação direta ou participante como técnicas de coleta de dados. No que tange a essas técnicas, respaldam-se os achados de Boina, Souza e Avelar (2014). 
Time-driven ABC: análise bibliométrica de artigos acadêmicos divulgados em periódicos científicos entre 2004 e 2015

Terence Machado Boina, Ewerton Alex Avelar, Antônio Artur de Souza, Pierre Ohayon

A aplicação do TDABC foi feita notadamente no setor de serviços $(82 \%$ dos artigos), destacando-se hospitais, bibliotecas, hotéis, serviços de tecnologia da informação ( $\mathrm{TI}$ ) e serviços de logística. Os demais $18 \%$ dos casos se restringiram ao setor industrial. Não foram observados trabalhos desenvolvidos no setor primário, como agricultura, pecuária, pesca, mineração etc. Isso parece sinalizar uma lacuna e uma oportunidade a ser explorada pelos pesquisadores no desenvolvimento e aplicação de conhecimentos sobre a temática do TDABC.

Divergindo dos resultados do índice de Lotka, o estudo revelou elevado número de one-timers (autores com apenas uma publicação), corroborando os achados de Boina, Souza e Avelar (2014). Um parco número de autores publicou 4 ou mais trabalhos, o que poderia indicar aprofundamento da pesquisa e o avanço do conhecimento por parte deles, mas também a ascendência de um reduzido número de pesquisadores e, consequentemente, de seus possíveis vieses pessoais.

Além disso, os achados permitiram observar diversos benefícios e limitações no tocante ao TDABC. Corroborando, pelo menos em parte, os achados de Boina, Souza e Avelar (2014), o incremento na precisão do processo de apuração dos custos, com a consequente melhoria das informações para o processo decisório, e a oportunidade de verificar e gerenciar a capacidade ociosa do processo produtivo foram os benefícios mais frequentemente enfatizados nas pesquisas analisadas. Já as limitações mais reiteradas do TDABC foram a necessidade de um sistema de informações estruturado, o custo de coleta de dados, a elaboração das equações de tempo, o grau de subjetividade inerente ao método e os recursos consumidos que não possuem o tempo como variável de atribuição.

Apesar de suas inerentes limitações, acredita-se que este estudo seja significativo para o ensino e a pesquisa em Contabilidade e Administração por apresentar um panorama histórico das pesquisas acadêmicas desenvolvidas sobre um método de custeio amplamente difundido na literatura. O prosseguimento da pesquisa inicialmente empreendida por Boina, Souza e Avelar (2014) auxilia na consolidação do conhecimento sobre o TDABC, possibilita a descrição de outros achados, indica relativa 
Time-driven ABC: análise bibliométrica de artigos acadêmicos divulgados em periódicos científicos entre 2004 e 2015

Terence Machado Boina, Ewerton Alex Avelar, Antônio Artur de Souza, Pierre Ohayon

escassez de redes de cooperação entre pesquisadores, problematiza estratégias de pesquisa empregadas, demonstra emergentes segmentos de atuação dos estudos empíricos sobre o tema e apresenta críticas sobre o TDABC para a reflexão de acadêmicos, estudantes e profissionais do mercado.

Pesquisas futuras poderiam ampliar o escopo da análise com a utilização de outras bases de dados e trabalhos escritos em outros idiomas, assim como publicados em demais veículos de comunicação pública (anais de congressos, teses, dissertações, livros etc.).

\section{REFERÊNCIAS}

AKHAVAN, S.; WARD, L.; BOZIC, K. J. (2015). Time-driven Activity-based Costing More Accurately Reflects Costs in Arthroplasty Surgery. Clinical Orthopaedics and Related Research, 474(1):8-15.

BALAKRISHNAN, K.; GOICO, B.; ARJMAND, E. M. (2015). Applying cost accounting to operating room staffing in otolaryngology: time-driven activity-based costing and outpatient adenotonsillectomy. Otolaryngol Head Neck Surg, 152(4): 684-690.

BARDIN, L. (2009). Análise de conteúdo. (4. Ed). Lisboa: Edições 70, 281 p.

BARRET, R. (2005). Time-Driven Costing: The Bottom Line on the new ABC. Business Performance Management, 3(1): 35-39.

BASUKI, B.; RIEDIANSYAF, D. R. (2014). The Application of Time-Driven ActivityBased Costing in the Hospitality Industry: An Exploratory Case Study. Journal of Applied Management Accounting Research, 12(1): 27-55.

BEAULIEU, F.; LAKRA, A. (2005). Coverage of Criticism of Activity-Based Costing in Canadian Textbooks. Canadian Accounting Perspectives, 4(1): 87-109.

BLOCHER, E. J.; CHEN, K. H.; LIN, T. W. (2002). Cost Management: A strategic emphasis. (2. ed). Massachusetts: McGraw-Hill//rwin, 1010 p.

BOINA, T. M.; SOUZA, A. A.; AVELAR, E. A. (2014). Uma Análise Bibliométrica de Trabalhos Acadêmicos sobre o Time-Driven Activity Based Costing, publicados em Periódicos entre os Anos de 2004 e 2013. In: Congresso Nacional de Administração e Ciências Contábeis, 5, 2014. Anais... Rio de Janeiro, 2014. 
Time-driven ABC: análise bibliométrica de artigos acadêmicos divulgados em periódicos

científicos entre 2004 e 2015

Terence Machado Boina, Ewerton Alex Avelar, Antônio Artur de Souza, Pierre Ohayon

BRUGGEMAN, W.; ANDERSON, S. R.; LEVANT, Y. (2005). Modeling Logistics Costs using Time-Driven ABC: $A$ Case in a Distribution Company. Disponível em: $<$ https://ideas.repec.org/p/rug/rugwps/05-332.html\#biblio>. Acesso em: 01/jan/2015.

CAMPANALE, C.; CINQUINI, L.; TENUCCI, A. (2014). Time-driven activity-based costing to improve transparency and decision making in healthcare: A case study. Qualitative Research in Accounting \& Management, 11(2): 165-186.

CARDINAELS, E.; LABRO, E. (2008). On the Determinants of Measurement Error in Time-Driven Costing. Accounting Review, 83(3):735-756.

CLELAND, K. (2004). As easy as CBA? Financial Management, 82(9): 28-31.

COBB, I.; INNES, J.; MITCHELL, F. (1992). Activity-based costing: Problems in practice. Londres: CIMA, $36 \mathrm{p}$.

COKINS, G. Learning to Love ABC. (1999). Journal of Accountancy, 8:37-39.

COOPER, R.; KAPLAN, R. S. (1988). Measure Cost Right: Make the Right Decisions. Harvard Business Review, setembro-outubro, 66(5): 96-102.

DALCI, I. et al. (2010). Customer profitability analysis with time-driven activity-based costing: a case study in a hotel. International Journal of Contemporary Hospitality Management, 22(5): 609-637.

DALMÁCIO, F. Z. et al. (2007). Uma Aplicação do Time-Driven ABC Model no Setor de Serviço Hospitalar: a nova abordagem do ABC proposta por Kaplan e Anderson. Contabilidade Vista \& Revista, 18(2):11-34.

DEMEERE, N. et al. (2009). Time-driven activity-based costing in an outpatient clinic environment: Development, relevance and managerial impact. Health Policy, 92(23):296-304.

ECKERT, A. et al. (2012). A viabilidade da aplicação do método de custeio TDABC em uma empresa de mármores sob encomenda. Revista de Estudos Contábeis, 3(5):25-47.

EVERAERT, P.; BRUGGEMAN, W. (2007). Time-Driven Activity-Based Costing: Exploring the underlying model. Cost Management, 21(2): 16-20.

EVERAERT, P. et al. (2008). Sanac Inc.: From ABC to time-driven ABC - An instructional case. Journal of Accounting Education, 26:118-54. 
Time-driven ABC: análise bibliométrica de artigos acadêmicos divulgados em periódicos científicos entre 2004 e 2015

Terence Machado Boina, Ewerton Alex Avelar, Antônio Artur de Souza, Pierre Ohayon

FISHER, J. G.; KRUMWIEDE, K. (2012). Product Costing Systems: Finding the Right Approach. The Journal of Corporate Accounting \& Finance, 23(3):53-51.

GERI, N.; RONEN, B. (2005). Relevance lost the rise and fall of activity-based costing. Human Systems Management, 24:133-144.

GERVAIS, M. et al. (2010). Time-Driven Activity-Based Costing (TDABC): An Initial Appraisal through a Longitudinal Case Study. Journal of Applied Management Accounting Research, 8(2):20-40.

GIL, A. C. (1996). Como elaborar projetos de pesquisa. São Paulo: Ed. Atlas, 156 p.

GOSSELIN, M. (1997). The effect of strategy and organizational structure on the adoption and implementation of activity-based costing. Accounting, Organizations and Society, 22:105-22.

HEIN, N. et al. (2009). Aplicação do Custeio Baseado em Atividade e Tempo (TDABC) em Laboratórios de Análises Clínicas. Revista INGEPRO - Inovação, Gestão e Produção, 1: 82-94.

HIRSCH, M. L. (2000). Advanced management accounting. (2. ed). London: Thomson Learning, $712 \mathrm{p}$.

HOOZÉE, S.; BRUGGEMAN, W. (2010). Identifying operational improvements during the design process of a time-driven $A B C$ system: The role of collective worker participation and leadership style. Management Accounting Research, 21(3): 185-199.

HUANG, S.Y. et al. (2014). The application of the theory of constraints and activitybased costing to business excellence: the case of automotive electronics manufacture firms. Total Quality Management \& Business Excellence, 25(5):532-545.

KAPLAN, R. S.; ANDERSON, S. R. (2004). Time-driven activity-based costing. Harvard Business Review, 82(11):131-138.

. (2007a).Time-driven Activity-based Costing: a simpler and more powerful path to higher profits. Boston: Harvard Press, $266 \mathrm{p}$.

Management, 21(2):5-15.

KAPLAN, R. S.; NORTON, D. P. (2008). Mastering the Management System. Harvard Business Review, 86(1):1-17. 
Time-driven ABC: análise bibliométrica de artigos acadêmicos divulgados em periódicos científicos entre 2004 e 2015

Terence Machado Boina, Ewerton Alex Avelar, Antônio Artur de Souza, Pierre Ohayon

KAPLAN, A. L. et al. (2014). Measuring the cost of care in benign prostatic hyperplasia using time-driven activity-based costing (TDABC). Healthcare, 3:43-48.

LIU, L. Y. J. et al. (2008). A longitudinal study of the adoption of an activity-based planning system in the Crown Prosecution Service of England and Wales, United Kingdom. Journal of Accounting \& Organizational Change, 4(3):318-342.

MALHOTRA, N. K.; BIRKS, D. F. (2007). Marketing Research: an applied approach. (3 ed.). Milão: Prentice Hall, 1037 p.

MAROCO, J. (2010). Análise estatística: com utilização do SPSS. (3. ed.). Lisboa: Sílabo, $990 \mathrm{p}$.

McLAUGHLIN, N. et al. (2014). Time-driven activity-based costing: a driver for provider engagement in costing activities and redesign initiatives. Neurosurg Focus, 37(5): 1-9.

MISONO, A. S.; OKLU, R.; PRABHAKAR, A. M. (2015). Time-Driven Activity-Based Costing Trumps Traditional Cost Accounting for Radiologists. American Journal of Roentgenology, 204(2):55-64.

MORTAJI, S. T. H.; BAGHERPOUR, M.; MAZDEH, M. M. (2014). Fuzzy Time-Driven Activity-Based Costing. Engineering Management Journal, 25(3): 63-73.

NASCIMENTO, A. R. et al. (2009). Disclosure social e Ambiental: análise das pesquisas científicas veiculadas em periódicos de Língua Inglesa. Contabilidade Vista \& Revista, 20(1):15-40.

ÖKER, F.; ADIGÜZEL, (2010). H. Time-Driven Activity-Based Costing: An Implementation in a Manufacturing Company. The Journal of Corporate Accounting \& Finance, 22(1):75-92.

OLIVEIRA, M. C. (2002). Análise dos Periódicos Brasileiros de Contabilidade. Revista Contabilidade \& Finanças, 29:68-86.

PERNOT, E. et al. (2007). Time-Driven Activity-Based Costing for Inter-Library Services: A Case Study in a University. The Journal of Academic Librarianship, 33(5):551-560.

PORTER, M. E.; KAPLAN, R. S. (2014). How Should We Pay for Health Care? Harvard Business School. Disponível em: <http://www.hbs.edu/faculty/Publication\%20Files/15041_1af09bde-47f9-4364-bad6-aaac464be909.pdf>. Acesso em: 05/jul/2015.

RATNATUNGA, J.; WALDMANN, E. (2010). Transparent Costing: Has the emperor got clothes? Accounting Forum, 34:1-30. 
Time-driven ABC: análise bibliométrica de artigos acadêmicos divulgados em periódicos científicos entre 2004 e 2015

Terence Machado Boina, Ewerton Alex Avelar, Antônio Artur de Souza, Pierre Ohayon

RATNATUNGA, J. et al. (2012). Cost Management in Sri Lanka: A Case Study on Volume, Activity and Time as Cost Drivers. The International Journal of Accounting, 47(3):281-301.

SAMPIERI, R. H.; COLLADO, C. H.; LUCIO, P. B. (2006). Metodologia de pesquisa. (3. ed.). São Paulo: MacGraw-Hill, 583 p.

SAUNDERS, M.; LEWIS, P.; THORNHILL, A. (2009). Research methods for business students. (5 ed.). Pearson Education, 768 p.

SOUZA, A. A. et al. (2010). Análise da aplicabilidade do time-driven activity-based costing em empresas de produção por encomenda. Revista Universo Contábil, 6(1): 6784. $7(2): 23-45$.

(2012). Aplicação do time-driven ABC em uma empresa varejista. ABCustos,

STOUTHUYSEN, K. et al. (2010). Time-driven activity-based costing for a library acquisition process: A case study in a Belgian University. Library Collections, Acquisitions, \& Technical Services, 34(2):83-91.

TANIŞ, V. N.; ÖZYAPICI, H. (2012). The Measurement and Management of Unused Capacity in a Time Driven Activity Based Costing System. Journal of Applied Management Accounting Research, 10(2).

VARILA, M. et al. (2007). Detailed cost modelling: a case study in warehouse logistics. International Journal of Physical Distribution \& Logistics Management, 37(3): 184-200.

WERNKE, R.; JUNGES, I.; LEMBECK, M. (2015). Comparativo entre os métodos UEP e TDABC: estudo de caso. Revista Ambiente Contábil, 7(1):51-69.

YILMAZ, R. (2008). Creating The Profit Focused Organization Using Time-Driven Activity Based Costing. In: EABR \& TLC Conferences Proceedings - Salzburg, Áustria, Disponível em: <http://www.ibrarian.net/navon/paper/Creating_The_Profit_Focused_Organization_Usin g_Ti.pdf?paperid=12867012>. Acesso em: 01/jul/2015.

Data de Submissão: 04/10/2015 Data de Aceite: 17/05/2016 